\title{
THE SITUATION OF A SPINAL UNIT IN AN ACCIDENT HOSPITAL
}

\author{
By F. W. MeINeCKe, M.D. \\ Spinal Injuries Centre of the Surgical Department of the Berufsgenossenschaftlichen, \\ Krankenanstalten Bergmannsheil, Bochum, Germany
}

THE Ruhr area is the centre of coal-mining and heavy industry in Germany. The great danger of accident in these industries is well known. It is for this reason that the Mutual Accident Insurance Association of the Mining Industry, the Bergbau Berufsgenossenschaft, decided at an early date to establish its own hospital for its insured. Here, all facilities for treatment of accidents and professional diseases from the very beginning up to partial or complete recovery are available. In I890, the 'Bergmannsheil' in Bochum was opened. This name is closely connected with the development of accident surgery in Germany. Out of the number of directors, Magnus and Bürkle de la Camp might be mentioned in particular. A second hospital was instituted later, the 'Bergmannsheil' in Gelsenkirchen-Buer. For the first time an Employers' Liability Insurance Association had herewith established special accident hospitals. It is the only one in Germany to maintain its own hospitals. All others belong to respective 'Krankenhausvereinen' (Hospital Associations).

The working conditions in the mines favour accidents which quite frequently cause paraplegia. Before the coal-mines had begun to be shut down, the Mutual Accident Insurance Association for the Mining Industry always had the comparatively highest quota of paraplegics out of all other Employers' Liability Insurance Associations. In I930, Haumann published a monograph in which he discussed details of the treatment of paraplegia and its results. It is quite interesting to study this publication today.

We can see that there have always been paraplegics among our material. Their concentration in one unit, however, was not effected until I952, through the initiative of Bürkle de la Camp. Before that date this had not been possible on account of lack of space as a result of war damages. Of the 35 beds of this unit, 12 to 15 were on the average taken up by paraplegics, the remainder by injuries other than paraplegia. The results of treatment of paraplegics improved conspicuously during the following years. The reasons for this improvementsuch as better means of comparison and a consequently wider experience of the nursing staff, mutual influence of the patients, etc.- - need not be elaborated here. In 1962 all industrial enterprises and contracting hospitals were instructed to transfer paraplegics of the mining industry to Bochum immediately after the accident. At the same time Professor Bürkle de la Camp started the establishment of a special department for paraplegics attached to the surgical department of the 'Bergmannsheil'. The consolidation and extension thus begun was continued by his successor Professor Jörg Rehn.

Within the surgical department with a total of 350 beds, the spinal unit has a complement of about 35 beds today. They are reserved primarily for injured of the coal-mining industry and other Employers' Liability Insurance Associations. Paraplegics insured by other insurance companies are equally 
admitted, provided there are vacancies. The number of these patients is increasing every year. Due to the insufficient total number of beds in special centres for spinal cord injuries in Germany, we have to refuse every year about 60 to 80 acute traumatic paraplegics who are not insured with an Employers'Liability Insurance Association. The fate of these patients does not have to be described here.

The head of the spinal unit is directly responsible to the director. Our hospital also includes a medical and a neurological department as well as an institute for lung function research and a pathological institute.

Questions of location and space do not have to be discussed. Plans for rebuilding the spinal centre are at present being worked out and an extension is being considered.

The advantages resulting from integration of a spinal centre into an accident hospital are quite evident. Frequently cases of acute traumatic paraplegia are associated with other injuries which do not seldom require immediate surgical measures. In the first few days after accident, the expectation of life of the acutely injured depends in many cases upon the early diagnosis and treatment of the associated injuries. Thus the injured becomes mainly a surgical problem, and this is not on account of the indication for laminectomy but because of the associated injuries.

Diagnosis and results of treatment are dependent upon experience and daily practice. In joint discussions the surgeon and the doctor in charge of the spinal centre will consider the particular diagnostic and therapeutic aspects of the individual patient. An experienced surgeon is always at hand, and the X-ray department, operating theatres and the laboratory are on duty day and night. An anaesthetist who is familiar with the peculiarities of paraplegia is alway on call. All medicaments necessary, including blood and blood surrogates are in stock. In fractures of tubular bones, for example, we have been able in the last few years to apply also to paraplegics the recent methods of osteosynthesis which are being practised daily at our hospital for non-paralysed patients. These methods offer great advantages which we will discuss elsewhere.

Diagnosis and treatment of traumatic shock are part of the basic knowledge of every accident surgeon as well as every anaesthetist and the whole of the nursing staff are also familiar with the conditions of shock. Exact blood-gas analyses which can at all times be provided by our institute for lung function research are a valuable supplement to our clinical methods of investigation. Thus the indication for a tracheostomy may be narrowed down. After a tracheostomy has been performed a blood-gas analysis helps considerably in deciding whether assisted or artificial respiration is required. In this connection, an anaesthetist who is especially familiar with these measures is of invaluable help. By such team-work the duration of tracheostomy respiration may be cut down to a minimum.

The signs of sudden heart failure are known to all those working at our hospital. During external massage of the heart, all preparations for a thoracotomy are automatically made in order to be able to start direct massage immediately if this should be necessary. Frequently the life of a patient can be saved by a well-organised co-operation.

At our hospital the neurologist can be consulted at very short notice and often proves very helpful in the assessment of an increasing paralysis when one's 
own diagnosis needs confirmation. Nerve injuries which were not caused by spinal cord injury can be evaluated and excluded together. In the treatment of psychiatric cases, such as attempted suicide, when psycho-pharmaceuticals have to be applied, we profit by the neurologist's experience. He also plays a significant role in the assessment of additional skull-brain trauma and in judging the necessity of operative measures. With the aid of the EEG it is easier for him to diagnose permanent organic damage of the brain. In our routine work the collaboration of neurologists and medical officers of the spinal centre have always been profitable.

The medical specialist may often have a decisive word as to when older patients or those with serious general diseases may be operated on. Diseases of the lungs, of the circulatory system and of the liver as well as pre-uremic and uremic conditions can frequently be controlled more effectively with his assistance. $\mathrm{He}$ is of equal help in diagnosing and treating thrombosis and embolism.

Also, in late complications our hospital with its space, instruments and staff presents great advantages. It will suffice to mention fractures of long bones, operations on tendons, muscles and nerves, pressure sores and stomach ulcers. We do not have an urologist among our staff, which is indeed a definite drawback, and there ought to be one who could at least be consulted. But as accident surgery is based on a good general surgical training, we are able ourselves to carry out a large part of the urological measures required.

The points of view presented here are not based on theoretical considerations; they are the results of excellent and harmonious team-work among the different departments of our hospital. From this fact an important psychological effect has resulted: all physicians and surgeons involved in our work have developed an attitude towards paraplegia which is free from any defeatist tendency. The same is true of the nursing staff. Their average working time exceeds by far that of comparable professional groups. The opportunity to fulfil a true humanitarian task and the many varieties of their responsibilities bind these people to their hard work. In the course of the years we have been able in the spinal unit to build up a staff of high standard. The paraplegics themselves are feeling happy in their invironment and have a good relationship with the other patients at the hospital.

All of those involved in the treatment of paraplegia have learnt a great deal in the past years. The process of building up this unit was hard and difficult and there still remains a sufficient number of wishes which are not as yet fulfilled.

The mortality rate of acute traumatic spinal cord patients who were admitted within two weeks after the accident has decreased considerably and the total time of treatment has been largely reduced. Sir Ludwig Guttmann has stressed time and again that the special field of the head of a spinal cord injuries centre is of secondary importance; important alone is that he is familiar with all the many aspects of paraplegia and tetraplegia and devotes his whole time to this special field of medicine, and that he instructs his team in the special conditions resulting from paraplegia.

It is necessary that the head of a spinal centre is not limited in his freedom of action. He is the one who by reason of his special experience has to co-ordinate the measures which are indicated, and he also has to carry the full responsibility for his unit as other specialists do for their units. 
The Employers' Liability Insurance Associations have acted consistently in accordance with the favourable results obtained in a centre for spinal cord injuries which is integrated into an accident hospital.

New centres are being built and out-dated departments are to be rebuilt or extended.

\title{
THE ORGANISATION OF A SPINAL INJURIES UNIT AT ROYAL PERTH HOSPITAL, PERTH, WESTERN AUSTRALIA
}

\author{
G. M. BedBrook, O.B.E., M.S., F.R.C.S., F.R.A.C.S. \\ Department of Paraplegia, Royal Perth Hospital, Perth, Western Australia
}

WITH the development of spinal units in many cities of the world, there will be variety in methods of inauguration and organisation of services that have become accepted parts of hospitals or medical centres. This mode has largely depended on the surgeon or physician who has had the primary interest in such patients. Thus the neurosurgeon, orthopaedist, urologist and physical medicine physician will be found in the vanguard of that ever-increasing group who will care for such patients.

\section{HISTORICAL}

Australia now has four well-developed centres. Of these, the centre in Perth, Western Australia, developed first in 1954, followed by Melbourne, Victoria, in 1956. Each developed differently.

In Perth, during I953, it became apparent that a number of paraplegics were hospitalised in various wards of Royal Perth Hospital. With the co-operation and consent of senior members of the clinical staff, to whose vision Western Australia can be for ever grateful, and with the help of the medical superintendent, the then in-patients were collected together into an orthopaedic ward at the Infectious Diseases Branch at Shenton Park-later to become the Royal Perth Rehabilitation Hospital.

As a member of the orthopaedic department, the author was asked to assume clinical responsibility, and so a unit was inaugurated as part of the orthopaedic department. All acute cases were admitted to the main orthopaedic department wards at the parent hospital and transferred at the end of five or six weeks to Shenton Park for further rather limited physical care and rehabilitation which was then available. However, a start had been made. Eventually, two old wards were occupied, and rapidly 20 beds were in use. This unfortunate division of the unit remained until 1963-64, when improved facilities (theatres, laboratories, $\mathrm{X}$-ray) allowed the reception of acute cases at Shenton Park.

By mutual arrangement, and with the help of the Australian Medical Association, by 1956-67 all cases of spinal injuries in Western Australia were directed to the unit, so that a really State unit was established.

Steady growth of the unit resulted in the independence of the unit by 1957-58 